\title{
Shared reading of children's interactive picture books
}

\author{
Claire Timpany, Nicholas Vanderschantz, Annika Hinze, \\ Sally Jo Cunningham, Kristy Wright \\ Dept. of Computer Science, University of Waikato, \\ Private Bag 3105, Hamilton New Zealand \\ \{ctimpany, vtwoz, hinze, sallyjo\} @waikato.ac.nz, \\ kaw37@students.waikato.ac.nz
}

\begin{abstract}
We report on a study of children and parents shared reading of interactive printed books. We investigated the differences between books with interactive features and books with expressive typography in order to evaluate which features within a book encouraged interaction between the reading participants and the book. 11 parent and child groups took part in the study that involved three observed reading sessions. From our observations we offer suggestions for the development of books and eBooks to encourage shared reading practices.
\end{abstract}

\section{Introduction}

The purpose of our study was to observe and subsequently evaluate shared reading between children and parents. By focusing on differences between books with interactive features and books with expressive typography, the aim of our study was to evaluate which features within a book aided interaction both between the shared reading participants and with the physical book. Children's books are an important learning device for young readers. In a picture book the words and illustrations are equally important to the story. Both pictures and words work together to create one unified story [1]. Picture books are not simply limited to supporting literacy, but instead promote wider-learning through aspects of problem solving, socialization, hand eye coordination, creativity and an understanding of the world [2]. Interactive eBooks and digital libraries provide opportunities for developing books and collections that enhance the interactive reading experience and could further enhance the shared reading experience.

\section{$2 \quad$ Related Work}

The significant related work to our study includes the literature around shared reading, interactive books and pictures, and expressive typography.

adfa, p. 1, 2011

(C) Springer-Verlag Berlin Heidelberg 2011 


\subsection{Shared reading}

We here consider shared reading to be the activity of a child and adult reading together. This practice is recommended 'to promote students' understanding and engagement with a text" [3]. Shared reading builds on the act of reading aloud which is beneficial for enabling children to hear language fluency, broaden their vocabulary and improve their knowledge of the world [4], in reading aloud situations the child is more passive than in a shared reading experience. In shared reading adults act as mediators and helping in the transition between the child not being able to read, and the child reading independently. Shared reading, consequently, is an important learning tool, promoting discussion, questions and a fun learning environment.

Participating in shared reading extends traditional schooling practices, teaching the child that they become a partner in communication when interacting with text [5]. This means that shared print experiences do not only enhance literacy development, but the communication skills of the child in general. Certain features and criteria enable shared-reading to be more productive. A book chosen for shared reading should invite involvement from both the child and the parent [2]. The language within the book should be age appropriate, and should support the child in reading and understanding the book. This means that the child is not required to know or understand all of the words and meanings within the book to gain from the reading experience. Reutzel and Cooter discuss how "shared reading books should have literary merit, engaging content, (both fiction and non-fiction) and high interest" [7]. The act of shared reading can be undertaken in a variety of ways, with the general consensus being that any form of shared reading is better than none at all. However, Girolametto \& Weitzman discuss three key behaviours and their associated techniques designed to gain responses from young readers and promote further learning and engagement: child-oriented behaviours, interaction-promoting behaviours, and language-modelling behaviours [8]. These responsive behaviours rely on parents reacting to situations and taking action accordingly and are expanded on by Ezell and Justice [8] in the context of shared reading.

- Child Oriented behaviours "follow the child's lead, pace and topic" [8]. In a shared reading environment, this means responding to the child's engagement and encouraging them to take the lead. This is important for promoting independent questions and observations from the child. The potential interactions of the child vary greatly according to the child, ability, understanding and willingness to engage.

- Interaction-Promoting behaviours "are used by responsive adults to engage children in conversation" [8]. This behaviour is utilised to encourage interaction and engagement from children who are somewhat reserved from the reading session. By asking the child thought-provoking questions, specifically who, what, when, where, why and how [8], the child will become more involved in the shared reading session. Interaction-promoting behaviours have the potential to encourage children to initiate interactions with books. Utilizing interaction-promoting behaviours effectively can therefore lead to child-oriented behaviours as the child 
instigates the discussion, resulting in a wider range of shared reading techniques and therefore greater potential for learning.

- Language Modelling behaviours are "used by responsive adults to extend children's language and literacy involvement to provide models of more advanced forms and features of oral and written language" [6]. This is seen most commonly through pointing to and identifying features of the story and book - whether it is objects, characters, letters or other features within the picture book. This labelling provides clarity and understanding in the context of the picture book, as applied to concepts in the child's environment [8].

\subsection{Importance of Pictures}

Bloom [9] states that children think and learn through both the words and pictures. Including imagery within a children's book enables a child to grasp concrete ideas through the "cross over and discovery of meaning in nonverbal representations" [10]. Pictures are a representation of the story, allowing children to grasp meaning even when the literature itself is above their reading ability. Within picture books, "art contributes so much to the emotional and cognitive impact of a story" [11]. The images help to convey emotions, reactions, and body language to children. These are important social and behavioural skills to learn from a young age. Consequently, the appropriate design and composition of images on the page is essential to a successful, engaging children's picture book.

\subsection{Interactive books}

At the most basic level, interactivity within books can be understood as becoming aware of "a book's unique physical structure, [bringing attention] to the momentous moment: the turning of the page" [12]. However, 'interactive' is a broad term that encompasses a wide range of variables. Bongers \& van der Veer discuss how "an interaction can be described in several layers, taking the user from a goal and intention, formulating a task and subtasks, carrying out these actions whilst receiving feedback on the physical level, and evaluating the result" [13]. 'Interaction' varies greatly between children and age groups [14]. From a previous survey of children's interactive books, we observed that interactivity is a continuum with books demanding different types of interaction so that the content can be consumed by the reader. Interactive books include features that engage the reader in either physical of intellectual interactions with the books and its content [15]. Physical interactions can occur at different levels, from pop-ups and opening additional pages to lifting flaps, tactile content or creating or re-arranging content. Intellectual interaction can guide the reader in a non-linear course through content, get them to solve puzzles or make decisions to effect the outcome of the story. How we understand which books engage a child in either physical or intellectual interactive experiences is discussed by Timpany and Vanderschantz [16] where they explain thatmost interactive books only appeal to just one area or the other. 
Digital interactive books offer new opportunities for added interactive value not available in printed books. The level of interaction in different types of digital books ranges from basic interactions in eBooks, video, audio and interactive elemnts in enhanced books and interactive eBooks where engagement with the storyline is increased beyond the experience available in printed media [17]. Itzkovitch [17] explain that in digital books there is the opportunity to create meaningful interaciotns which enhance the engagement with the storyline in ways that printed books cannot, but the value of this interactive ability is yet to be fully explored.

From current understanding of what interactive books are in both printed and digital environments, we can broadly define them as books which use physical or intellectual enhancements to engage the reader in activities that enhance the storyline.

\section{$2.4 \quad$ Expressive Typography}

Expressive typography refers to typography that differs in some form from the typical, typed text. Phinney and Colabucci discuss the varying types of expressive typography, listing variations of typeface or the size, style (weight or italics), colour, or position of the type [16]. They stress that expressive typography is not limited to plain text, and that it can be a substitute for illustrations or literary devices to advance the story [16]. They found that the inclusion of expressive typography within children's books is often used to emphasise specific elements of the story [16], and is used as both a literary device and to provide a point of interest. Thus the typography itself may mimic the illustrative style of the book, may relate to the message of the story, or may provide the reader context for further understanding of the word or story in general. Therefore we can define expressive typography in books as being the elaboration or variation of typography to enhance the meaning of the words and the story reading experience.

\section{Study Methodology}

For this study, 11 families were invited to participate in a total of three, half hour shared-reading observation sessions. The participants were recruited through the personal contacts of the researchers. The citieria for selection was that child was aged between 4 and 7, and the family were comfortable angaging in shared reading for the purpose of this study.

The sessions. These sessions were video recorded and manual field notes were made by the researcher. Each session included an observation of shared reading and a post-observation semi-structured interview. An initial interview was conducted by the researcher before the first observation session. This interview recorded demographic information and sought an understanding of the child and parents' reading habits. Interviews and observations were conducted with all 11 families by the same researcher in the homes at times that were selected by the families.

After the initial interview, the child and parent then took part in the first observation, a shared reading of the control book, 'Edward the Emu' by Sheena 
Knowles. After the parent and child had read the book they were asked questions about interactions they had engaged in while reading and what each of them liked most about the book they had just read. Information about the reading environment, duration of the session and the time of day were noted by the researcher after each observation.

The second session involved the researcher observing the parent and child participating in shared reading with three interactive books. Two of these books were chosen by the child and parent from the child's current collection. The researcher asked the participants to select books that the participants believed to contain interactive elements. The third book - 'Blue 2' by David Carter - was provided by the researcher as a control book. Observations focused on how the interactive elements of the book affected the way the readers used the book and read the story. After each book, the researcher conducted a short semi-structured interview asking them about how they used the features of the book and what they liked most about it.

The third observation was run in the same way as the second, but with three books that contained expressive typography. The participants selected two books from their own collection which they deemed to contain expressive typography. The third book was provided by the researcher - 'Beautiful Oops' by Barney Saltzberg. The observations of the shared reading conducted using these books again focused on recording details about the interactions the parent and child had with the book as well as with each other and how the use of expressive typography within the book influenced these interactions. Again a semi-structured interview followed the observations.

In all interviews, questions considered interactions driven by physical enhancement or intellectual enhancement in the book, as well as non-book driven interactions.

The Books. We describe here the books used for the observations. Edward the Emu was chosen as the control book for its appealing illustration and story. This children's picture book provides no features that encourage interaction, meaning that interaction must be driven purely by the parent and child within the shared reading environment. Blue 2 is an interactive children's book that features pop-ups, and requires the reader to search for the blue ' 2 ' on each page by following the written clues. These written clues are somewhat abstract, and do not read with the same flow or story structure as a typical children's book. The interactive books chosen by the parents from their personal collections included search-and-find books, pop-up or liftthe-flap books, and books that included toys, puppets and different textures. The expressive typography within Beautiful Oops is based on a hand-drawn approach that attempts to mimic a child's writing and drawing. In contrast, the books chosen by parents from their personal collections included more typical examples of expressive typography: changes in font, size, colour, and placement of text.

The Participants. Our participant sample included 11 parents and their children who were aged between 3 and 6 years old. Table 1 details our participant sample. When asked in a pre-interview about their current reading practices all participants stated that they take part in shared reading with their children on a daily basis. Nine of the 11 children look at books independently every day, and the remaining two would use books independently once a week ( $\&$ K $)$. 
Table 1. Participant Sample

\begin{tabular}{|l|l|l|l|l|l|l|l|l|l|l|l|}
\hline ID & A & B & C & D & E & F & G & H & I & J & K \\
\hline Age & 4 & 3 & 4 & 5 & 4 & 3 & 6 & 4 & 6 & 5 & 6 \\
\hline Child & F & M & M & M & F & F & F & M & F & F & M \\
\hline Parent & F & F & F & M & F & F & F & F & F & F & M \\
\hline
\end{tabular}

\section{$4 \quad$ Results}

We discuss here the results of our three interview and observation sessions.

\subsection{Control Picture book - Edward the Emu}

Even though the control book included no elements of book-driven interaction, ten of the parents asked children questions throughout the shared reading. In addition, eight of the eleven children asked their parents questions throughout the observation session. Nine of the children also interacted with the book by physically touching the pages, whilst seven of the children pointed out elements within the book throughout the shared reading sessions. When asked what their favourite part of the book was, all of the children participants chose the illustrations. Five of the children also stated that they enjoyed the message of the book, and were able to easily identify the message as 'the importance of being true to yourself'. When parents were asked the same question, they mentioned that they enjoyed the illustrations (eight parents), the rhyming and rhythm of the text (six), the overall message or moral of the story (four) and the overall level of the book and easy readability (three).

\subsection{Interactive Books}

Each family was observed with Blue 2 and two additional interactive books from their personal collection. Written clues used in Blue 2 are somewhat abstract and are grouped in threes, and do not read with the same flow or story structure as typical children's books. Consequently, when reading through the book, one parent did not even realise that the book contained text until almost half way through. A total of four of the eleven parents found the story difficult to read due to vocabulary and flow of text, and consequently the physical interaction rather than the shared reading was the focus. All participants, both children and parents, physically interacted with Blue 2 throughout the observed reading sessions.

Five of the parents were concerned by the delicate and intricate nature of Blue 2, these included the parents of two three-year-olds, two four-year-olds and one five-year-old. Parent B stated that the book was "maybe too delicate for the age" (3 years) and parent D said they were "worried about it breaking". All five parents stated that they changed their interactions due to the delicate nature of the book. This was observed as the parent undertaking the interactions rather than the child and the parent 
encouraging the child just to watch, which was not observed with other interactive books.

Two of the eleven parents enjoyed the fact that Blue 2 could be read differently each time, by reading it out of order or by finding different features to talk about each time, including both the physical aspects of the book and the story line. Parent D stated that the book enabled you to "re-read it without getting bored", and Parent J stated that you "could read it differently every time".

Two of the parents stated that the interactive books that they owned (lift the flaps) were no longer read or fully utilised by the child because the interactive features are superficial to the story and tend to have little or no impact on the way the story is read. Parent D stated about his child that "when he was younger and looking at pictures he would flip them to be involved, but now he focuses just on the story. If the flaps were more important to the story they would be more effective". It is relevant to note that Parent D commented on the ability to read Blue 2 differently each time and the importance of this within the shared reading environment. Parent G believed that 'lift the flap' features are "only good if they can't read on their own" as they often only include added illustrated content, rather than adding to the story.

Six of the children stated that finding the Blue 2 was their favourite part of the book, whilst the remaining five children pointed to specific pages that they believed were the best. Similarly, when asked why the pop-up features were in the book, six of the children said that they were included to increase the complexity or difficulty of the book. Child I stated that the pop ups "make it hard to find and makes it fun" (I), whilst Child D stated that the pop up features "make [the book] more exciting ... cool things to touch ... I liked it because it was hard".

In six of the 22 observations involving the personal collection of interactive books, the children stated that the illustrations were their favourite aspects, while eleven of the children stated that the interactive elements were their favourite features.

\subsection{Expressive Typography Books}

Each family was observed with Beautiful Oops and two expressive typography books from their own collection. Only one parent stated that the expressive typography within Beautiful Oops changed the vocal expression they used when reading. In contrast, all parents noted that the expressive typography present in books from their personal collections affected the way that they read the text. For example, when observing the books from the personal collections, Parent F stated that the expressive typography made her "[place] emphasis on those specific words" and Parent B stated that the use of different sized typography changed the voice that she used when reading, "with big writing you read it louder, more impressive. With little text you use a little voice".

Three of the parents noted that Beautiful Oops had the potential to be read differently - both in subsequent reading sessions and as the child got older. Parent E stated that the expressive typography within the book would enable her to "talk about the text as she got older", allowing for a further explanation of the meaning of words 
and the relation between text and image. Only one parent (B) noted the potential for this within an expressive typography book that was from their collection.

Six of the parents were observed asking questions when reading Beautiful Oops, these included "what's that?" and "what does it look like?". Whilst the text of the book itself did not promote questions, the parents clearly believed that the nature of the imagery and layout lent itself to a question and answer interaction.

Within 14 of the 22 personal expressive typography books, the children stated that the illustrations were the favourite aspect of their books. Two of the children stated that they liked the story content, and five children that they enjoyed the rhythm of text and typography. Whilst the children could not identify the feature as 'typography' they were able to understand the basic concept. For example, child D made a "hisssssssssss" noise and stated that she liked how the 'sound' was "written on the page" in a shape that mimicked that of the snake illustration.

Beautiful Oops also included aspects of physical interactivity. Within Beautiful Oops, 7 of the children stated that the interactive features were their favourite, and the remaining 4 stated that the illustrations were their favourite features.

When asked what they believed the purpose of expressive typography was, all eleven children understood that it was designed to help you read as well as to change the way specific words were read. These comments ranged from aspects of shape and colour to verbal cues. "Makes you whisper and be loud", "The letters look the same as the dog". Parent D stated that the "text [was] too cramped" within one of their own personal collection expressive typography books. This made it confusing for his child to read. The researcher noted that the child (who was reading) was unsure which word or group of text was next in sequence due to the scattered nature of the text.

\section{Discussion}

We acknowledge the effect of having a third party observing the reading sessions may have had on the reading experience. This may be seen through the parent or child be ing engaged more or less, or in a different way to how they would usually interact because of the researchers presence or the video camera. The researcher endeavoured to be as unobtrusive as possible throughout the session.

Our study has shown that the fundamental elements of the children's book such as effective illustrations and clear typography continue to be successful if implemented, and the interactive elements and expressive typography will aslo be successful if implemented in ways suitable for children.

Illustrations remain an important aspect within children's books, as discussed by Gibbons [19], Bloom [9] and Piro [10]. The illustrative content is engaging and memorable, and in turn aids the child in understanding and enjoying the text. Over the 22 observations of personal expressive typography books 14 children stated that the illustrations were their favourite aspects, whilst similarly 6 children from the 22 observations of personal interactive books made the same claim about illustrations. 4 children also identified the illustrations as their favourite features within Beautiful Oops. All children stated that the illustrations were their favourite aspect of Edward 
the Emu - the control Picture Book. Consequently, when designing children's books, effective illustrations can be applied to a wide range of books, including those with elements of expressive typography and interactivity. It would also be recommended to implement physical and intellectual enhancements within these illustrations.

The three 'responsiveness' behaviours [8] (child-oriented behaviours, interactionpromoting behaviours and language-modelling behaviours) as discussed in Section 2.1 help to engage both parent and child in the process. However, unless a parent is taught how to engage their child in this way, these behaviours will not occur. When designing a children's picture book it is consequently important to consider how the aspects of the book itself can promote these behaviours. Goodwin's discussion of shared reading promotes the idea that the practice should "invite involvement", giving the child a chance to push their level of understanding to a new level in an environment that encourages the child to take a chance [6]. The importance of this was observed within Blue 2, with six of the eleven children commenting on the difficulty of the interactive task adding to the overall enjoyment of the book. Consequently, the level of difficulty helps to encourage further learning from the child as well as have a direct impact on the level of engagement and enjoyment.

From our observations, we conclude that the interactive features within the children's picture book must have an impact on the story itself. Whilst 'lift-the-flap' features are effective with younger readers, the novelty wears off with older children. Even though Blue 2 is an interactive book that requires physical engagement (through touching and moving the book) and intellectual engagement (by searching for the hidden ' 2 '), the story itself is not engaging. Consequently the book is more of an 'activity' book than a 'reading' book for the age group observed. An effective children's interactive book must include an appropriate and engaging story that can be read within the shared reading environment, and must include interactive features that promote further engagement or have an impact on the outcome or reading of the story.

Expressive typography needs to be simple in order to be effective. Many of the children participants found the typography within Beautiful Oops hard to read, and there were further comments about the 'confusing' aspects of some books from personal collections. These included comments of using script, which was hard for young readers to read, as well as text in shapes being placed in different places on the page, meaning that young readers found it difficult to follow the flow of the story. This highlights the importance of readability over interactive features.

All parents within the study commented on the effect of expressive typography on their reading style - ranging from utilising voices as well as expression and tone. Whilst this is key within the shared reading environment, it is important to note that children's picture books tend to transition with the child as the young reader moves from listener to reader. Consequently when utilising expressive typography it is important to consider readability first and foremost. Even though this study included a wide age range of children, all were able to identify the purpose of expressive typography. If children are able to understand that this design feature is implemented to aide understanding and to imply emphasis, it is important that the typography itself is designed in such a way that the children can undertake this act. Beautiful Oops was perhaps the wrong choice for testing the control of expressive typography, as the 
typography itself was more difficult to read than a standard typed font. However this allows a further understanding of how important it is to consider not just aesthetics, but the practicality of typography used when designing children's books.

\section{Recommendations for children's interactive book design}

This paper reported on a study of shared reading between parents and children, including a wide range of books with varying levels of interaction from parent and child. Based on successful elements observed in our study, we now explore what implications for successful interactive electronic books (eBooks) that encourage shared reading.

Age-appropriate story and illustrations. Our observations confirm that successful children's picture books need to firstly include an engaging story that is appropriate for the age and reading level of the child. The story must have a rhythm that drives the story, and a message that relates to the real world and reaches the child at their emotional level. The illustrations must be appropriate for the text and be equally as engaging as the story itself, allowing younger children to 'read' the images and understand the combination of pictures and words. These illustrations must be designed and utilised in such a way that they support the story as well as the other features within the book. These observations hold for both conventional books and eBooks. It is also important that when creating interactive books that the interaction is age appropriate as well as appropriate for the story. In observations it was noted that the interactive features of Blue 2 were not engaging for readers at all age levels. This shows that the interaction and story level needs to both be carefully considered alongside eachother for age-appropriateness.

Engaging interactive features. Parents that engage in effective shared reading practices will find aspects within all children's books that can draw on a range of interactions, both physical and intellectual. All of the parents within the study participated in this way, however it is the parents that are not participating in effective shared reading practices that need to be catered for. Whilst it is understood that the asking of questions, from both parents and children, promotes wider learning and understanding, books must be designed to encourage this practice. This can be implemented by the inclusion of questions within the text of the book itself, or through the inclusion of imagery and elements that lend themselves to inquisitiveness from the child within the shared reading environment. Also, the book itself must encourage comments to be made by parents and children. Many comments noted throughout the study were centred on the interaction of characters - both in the story and the imagery - and the identification of elements. By designing a children's book that encourages the readers to 'look closer' - both figuratively and literally - shared reading practices including comments and questions will be encouraged of shared reading partners. Many of the interactive features currently seen in digital interactive books seem to be included for entertainment purposes, rather than to encourage shared reading and engage the child with the story. Interactive features included in digital books (sound, games, video, etc.), must tie very closely to the story. Presently 
many of the digital interactions seem distracting (particularly in-book games or puzzles that are rooted to a single page, unlike the Blue 2 puzzle that spans the book). It can also be argued that many eBooks today are designed for a single user, rather than for shared reading. Further research needs to be conducted to investigate how eBooks are used in shared reading and how their interactive elements influence the shared reading process.

In a digital library engaging interactive features could be included either within individual books or created in a way that creates connections between stories or ideas from stories to facilitate the shared reading experience beyond individual books. This may include having questions that fascilitate discussion between the adult and child or may be activities that bring together the ideas from several storylines. The possibilites of creating meta-interactive features in digitial libraries is an area that requires further investigation.

Adaptivity. As is often seen with young children's reading practices, the repetitive reading of a text lends itself to a child memorising the story and elements. Several of the parents within the observations noted the importance of being able to read the story differently each time or for there to be several levels or layers of interaction within a book that will appeal to readers of different ages. Consequently children's picture books need to include a level of adaptivity to allow the child and parent to interact with the book differently each time they read it. This adaptivity may be easier to include in electronic books. When designing children's books in the future it will be imperative to consider how one book can be adapted to provide new learning possibilities as the child grows. These adaptive qualities could relate to different storylines, different interactive activities, or different learning outcomes. We strongly believe that the features of interactivity that encourage shared learning will be applicable to books in both print and in electronic form (ebooks) and the design of these features needs to be explore.

When applying the idea of adaptivity to interactive books in digital libraries we need to consider that this may mean that the entire collection could be given different contexts as the age of the child increases or the library could be used as a way to adjust or refine the books that are offered based on the types of interaction that appeal to the child at present. Digital libraries could also manage changes in storylines or interactive features across a collection to adapt to the changing needs of the reader. The adaptivity of interactive books and their integration into digital libraries and how they can best support adaptive features is an area where the possibilities need to be explored further.

Digital Interactive Books. While this study only observed children and parents engaging in shared reading with printed books, we can still draw some recommendations from this study for the design of digital interactive books and their incorporation into digital libraries, which can be investigated further in future studies. This study explored the physical and intellectual interactions of shared reading with physical books, it is clear that similar interactions will be present in shared reading of eBooks on mobile devices. Interactivity in a book, whether printed or digital, falls into 2 areas depending on the types of interaction that it uses. Meaningful interaction is that which engages the reader and enhances the storyline, reading or learning 
experience through the interavtive experience. Inconsequential interactivity is often seen in the form of a game, or activities that are "for the sake of it", which are frequently adaptations of print books into eBooks [17] and add nothing to the storyline and can often distract from the story itself or hinder the learning experince. Digital interactions should create a value that is nor available in printed books [17]. When designing interactive books for children it is important to remember that the interaction should enhance the reading exerience for the child.

\section{$7 \quad$ References}

1. Galda, L.: Literature and the child. Wadsworth Cengage Learning, Australia (2014).

2. Freedman-De Vito, B.: Why reading is so important for children. Retrieved January. 6, 2010 (2004).

3. Worthy, J., Chamberlain, K., Peterson, K., Sharp, C., Shih, P.-Y.: The Importance of Read-Aloud and Dialogue in an Era of Narrowed Curriculum: An Examination of Literature Discussions in a Second-Grade Classroom. Lit. Res. Instr. 51, 308-322 (2012).

4. Rog, L.J.: Read, Write, Play, Learn : Literacy Instruction in Today's Kindergarten. International Reading Association, Newark, DE, USA (2011).

5. Rose, D.: Meaning beyond the Margins: Learning to Interact with Books. Semiot. Margins Mean. Multimodalites. 177 (2011).

6. Goodwin, P. ed: Understanding children's books: a guide for education professionals. SAGE, Los Angeles ; London (2008).

7. Reutzel, D.R., Cooter, R.B.: Teaching children to read: the teacher makes the difference. Pearson, Boston (2012).

8. Ezell, H.K., Justice, L.M.: Shared storybook reading : building young children's language $\&$ emergent literacy skills. Paul H. Brookes Pub., Baltimore, MD (2005).

9. Bloom, P.: How Children Learn the Meanings of Words. MIT Press, Cambridge, MA, USA (2002).

10. Piro, J.M.: The picture of reading: Deriving meaning in literacy through image. Read. Teach. 56, (2002).

11. Hall, S., Hall, S.: Using picture storybooks to teach literary devices: recommended books for children and young adults. Oryx Press, Phoenix, AZ (1990).

12. Selznick, B.: Caldecott Medal Acceptance. Horn Book Mag. 84, 393-406 (2008).

13. Bongers, B., Veer, G.C.: Towards a Multimodal Interaction Space: categorisation and applications. Pers. Ubiquitous Comput. 11, 609-619 (2007).

14. Lander, D.: Online learning: Ways to make tasks interactive. UltiBASE Httpultibase Rmit Edu AuArticleslander2 Htm. (1999).

15. Timpany, C., Vanderschantz, N.: A Categorisation Structure for Interactive Children's Books. Int. J. Book. 9, 97-110 (2012).

16. Timpany, C., Vanderschantz, N.: Using a Categorisation Structure to Understand Interaction in Children's Books. Int. J. Book. 10, 29-44 (2013).

17. Itzkovitch, A.: Interactive eBook Apps: The Reinvention of Reading and Interactivity, http://uxmag.com/articles/interactive-ebook-apps-the-reinvention-of-reading-andinteractivity, (2012). 
18. Phinney, T., Colabucci, L.: The Best Font for the Job. Child. Libr. J. Assoc. Libr. Serv. Child. 8, 17-26 (2010).

19. Gibbons, J.: Visual Literacy and Picture Books. Teach. Curric. 3, (1999). 